\title{
TWO NEW SPECIES OF ALLOGALUMNA (ACARI, ORIBATIDA, GALUMNIDAE) FROM MADAGASCAR
}

\author{
Sergey G. Ermilov ${ }^{1}$ and Josef Starý ${ }^{2}$ \\ ${ }^{1}$ Tyumen State University, Institute of Environmental and Agricultural Biology (X-BIO) \\ Lenina str. 25, 625000 Tyumen, Russia \\ E-mail: ermilovacari@yandex.ru; https://orcid.org/0000-0002-0913-131X \\ ${ }^{2}$ Biology Centre v.v.i., Czech Academy of Sciences, Institute of Soil Biology \\ České Budějovice, Czech Republic; E-mail: jstary@upb.cas.cz \\ https://orcid.org/0000-0002-9440-4254
}

Two new species of oribatid mites of the genus Allogalumna (Oribatida, Galumnidae) are described based on adult specimens from leaf litter in the Montagne d'Ambre National Park of Madagascar. Allogalumna paramadagascarensis sp. n. differs from Allogalumna madagascarensis by the morphology of notogastral porose areas Aa. Allogalumna paravojnitsi sp. $\mathbf{n}$. differs from Allogalumna vojnitsi by the morphology of notogastral porose areas $A a$ and length of lamellar setae. An identification key to Allogalumna-species from Madagascar is presented.

Key words: galumnid mites, morphology, systematics, Madagascar, Ethiopian region.

\section{INTRODUCTION}

Allogalumna (Acari, Oribatida, Galumnidae) was proposed by GrANDJEAN (1936) with Galumna alamellae Jacot, 1935 as type species. At present, Allogalumna comprises two subgenera (Ermilov \& KLimov 2017) and more than 50 species, having a cosmopolitan distribution. The generic and subgeneric diagnoses were summarized by Ermilov and KLimov (2017).

During taxonomic identification of a random set of the Madagascar oribatid mites (Ethiopian region) which were received from the collection of the Moravian Museum in Brno (Czech Republic), we found two new species of Allogalumna (both belonging to the nominative subgenus).

The oribatid mite fauna of Madagascar has been poorly investigated, and only six species of Allogalumna are known from this country so far (BALOGH 1960, Mahunka 1996): A. costata Mahunka, 1996, A. insolita Mahunka, 1996, A. longula (Balogh, 1960), A. madagascarensis (Balogh, 1960), A. pocsi Mahunka, 1996, and A. superporosa Mahunka, 1996. The main goal of this paper is to describe and illustrate these new species. An additional goal of this paper is to present an identification key to known Allogalumna in Madagascar. 


\section{MATERIAL AND METHODS}

Oribatid mites were collected in the Montagne d'Ambre National Park (Madagascar) during a long-term official cooperation between the Moravian Museum in Brno (Czech Republic) and Université d'Antananarivo (Madagascar) in 2010-2014.

Specimens were mounted in lactic acid on temporary cavity slides for measurement and illustration. Body length was measured in lateral view, from the tip of the rostrum to the posterior edge of the notogaster. Notogastral width refers to the maximum width of the notogaster in dorsal view (behind pteromorphs). Lengths of body setae were measured in lateral aspect. All body measurements are presented in micrometers. Formulas for leg setation are given in parentheses according to the sequence trochanter-femur-genu-tibia-tarsus (famulus included). Formulas for leg solenidia are given in square brackets according to the sequence genu-tibia-tarsus.

Drawings were made with a camera lucida using a Leica transmission light microscope “Leica DM 2500".

Morphological terminology used in this paper follows that of F. Grandjean (see ERMILOv \& KLIMOV 2017 for review and application).

The following abbreviations are used: $S=$ sublamellar line; $N=$ prodorsal leg niche; $E$, $T=$ lateral ridges of prodorsum; $r o, l e, i n, b s, e x=$ rostral, lamellar, interlamellar, bothridial, and exobothridial setae, respectively; $A d=$ dorsosejugal porose area; $D=$ dorsophragma; $P$ = pleurophragma; $c, l a, l m, l p, h, p=$ notogastral setal alveoli; $A a, A 1, A 2, A 3=$ notogastral porose areas; $m p=$ median pore; $i a, i m, i p, i h$, ips = notogastral lyrifissures; $g l a=$ opisthonotal gland opening; $a, m, h$ = subcapitular setae; or = adoral seta; $d, l, v, c m, a c m, u l, s u l, v t, l t=$ palp setae; $\omega=$ palp and leg solenidion; $a s=$ axillary saccule; $c h a, c h b=$ cheliceral setae; $T g$ = Trägårdh's organ; $I$, II = pedotecta I, II, respectively; $1 b, 3 b, 4 a, 4 b$ = epimeral setae; dis = discidium; $c p$ = circumpedal carina; $g, a g, a n, a d=$ genital, aggenital, anal and adanal setae, respectively; $i a d=$ adanal lyrifissure; $p o=$ preanal organ; $A p=$ postanal porose area; $\mathrm{Tr}, \mathrm{Fe}$, $\mathrm{Ge}, \mathrm{Ti}, \mathrm{Ta}=$ leg trochanter, femur, genu, tibia, tarsus, respectively; $p a=$ leg porose area; $\sigma, \phi$ $=$ leg solenidia; $\varepsilon=\operatorname{leg}$ famulus; $d, v, e v, b v, l, f t, t c, i t, p, u, a, s, p v, p l=$ leg setae.

\section{SYSTEMATICS}

Galumnidae Jacot, 1925

Allogalumna Grandjean, 1936

\section{Allogalumna paramadagascarensis sp. $\mathrm{n}$.}

(Figs 1-4)

Diagnosis. Body size: 315-348 × 232-265. Rostrum rounded. Bothridial seta long, slightly dilated in median part, ciliate unilaterally. Rostral, lamellar and interlamellar setae setiform, smooth, ro of medium size, le and in short. Dorsosejugal porose area oval. Dorsosejugal suture absent. Four pairs of rounded notogastral porose areas. Median pore present. Epimeral and anogenital setae short, setiform, smooth. Genital plate with one longitudinal strium in medial part. Postanal porose area oval. Solenidion of tibia IV inserted in the middle of the segment. Sexual dimorphism not observed. 
Description. Measurements. Body length 332 (holotype, female), 315-348 (four paratypes, two females and two males); notogaster width 249 (holotype), 232-265 (four paratypes). No clear differences between females and males in body size.

Integument. Body color brown. Body surface (including pteromorphs, subcapitular mentum, genital and anal plates, legs) sparsely microfoveolate (visible under high magnification, $\times 1000$ ). All leg femora and trochanters III, IV with rounded or elongate tubercles antiaxially. Genital plate with one longitudinal strium in medial part.

Prodorsum (Figs 1A, 2A). Rostrum broadly rounded. Sublamellar line slightly visible, thin, curving backwards. Prodorsal leg niches and lateral ridges of prodorsum well-developed. Rostral (32-36), lamellar (6-8) and interlamellar (2) setae setiform, thin, smooth, ro thickest. Bothridial seta (82-94) slightly dilated (in median part) and ciliate unilaterally. Exobothridial seta represented by alveolus. Dorsosejugal porose area (18-20 × 6-8) elongate oval, transversely oriented, located posterolateral to in.

Notogaster (Figs 1A, 2A-C). Dorsosejugal suture absent. Dorsophragma elongated longitudinally, with variable number of components. With 10 pairs of setal alveoli and four pairs of rounded porose areas, $A a(12-16)$ larger than others (8-12). Median pore present in
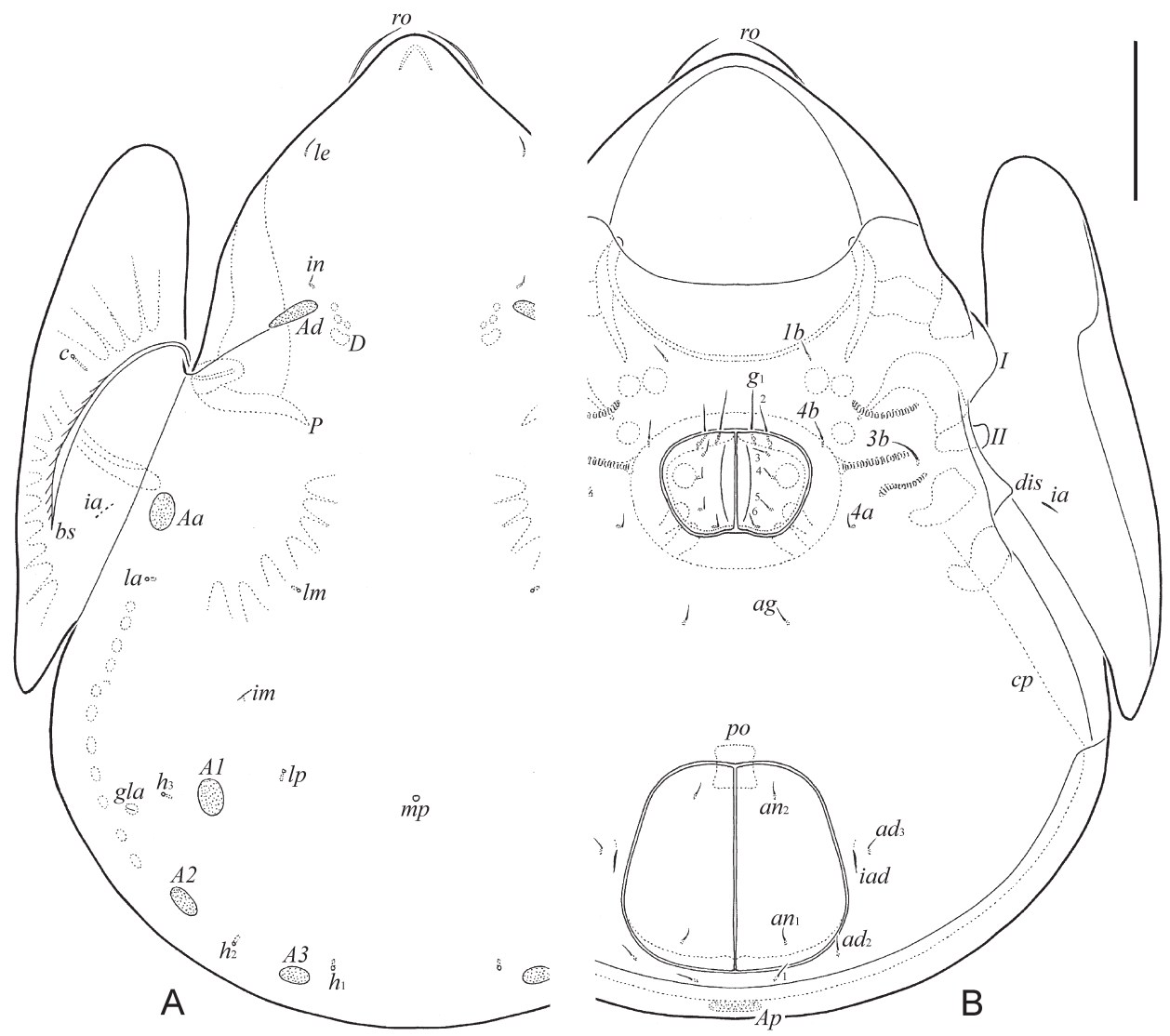

Fig. 1. Allogalumna paramadagascarensis sp. n., adult: $\mathrm{A}=$ dorsal view; $\mathrm{B}=$ ventral view (gnathosoma and legs not shown). Scale bar: $50 \mu \mathrm{m}$ 
both sexes, located between $A 1$. All lyrifissures distinct, im located between $l m$ and $A 1$, ip between $p_{1}$ and $p_{2}$, ih and ips close to each other, anterior to $p_{3}$. Opisthonotal gland opening located posterolateral to $A 1$ and distanced from it.

Gnathosoma (Figs 3A-C). Subcapitulum longer than wide: 82-90 × 73-82. Three pairs of subcapitular setae setiform, smooth, $a$ (14) longer and thicker than $m$ (10) and $h$ (6). Two
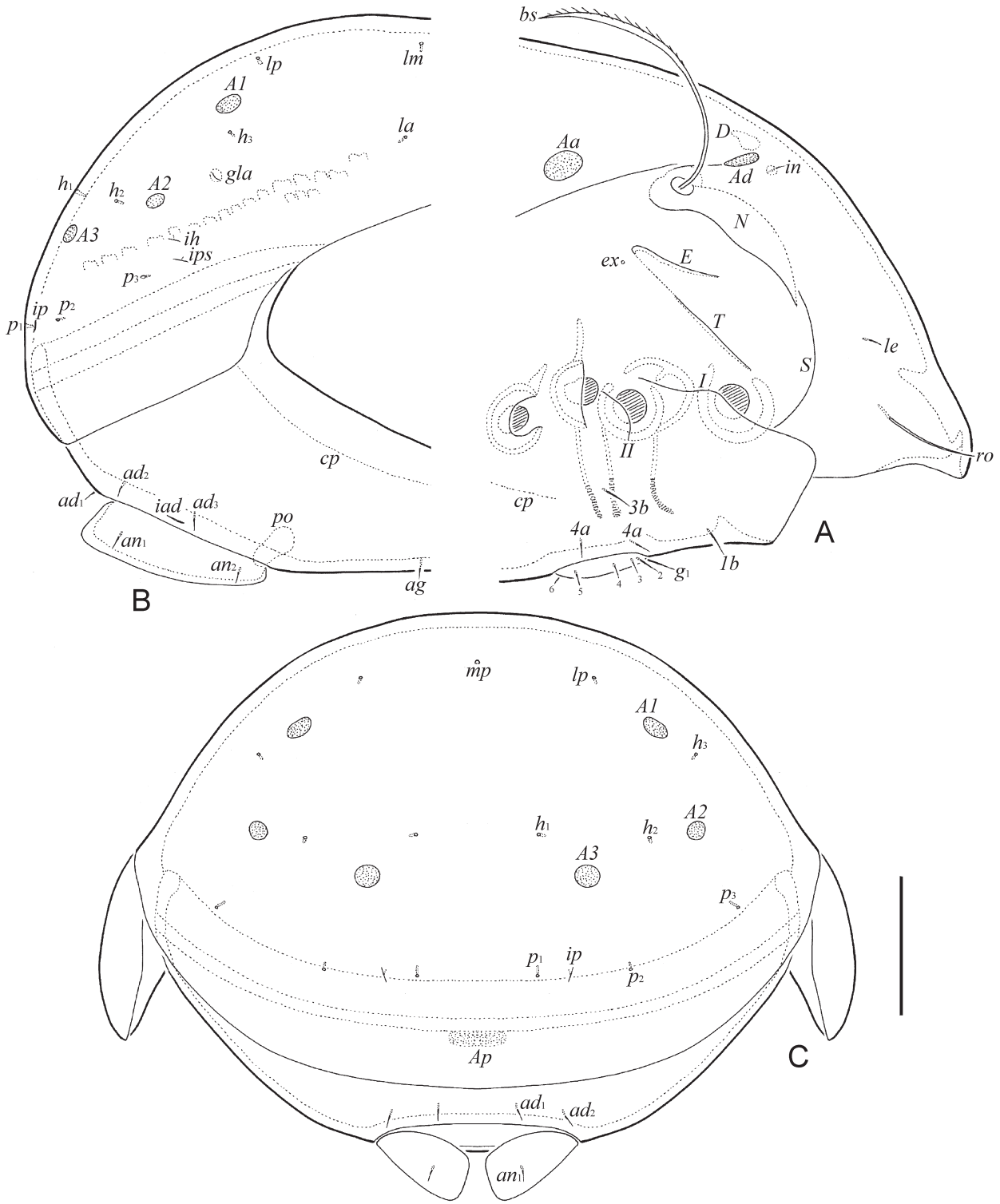

Fig. 2. Allogalumna paramadagascarensis sp. n., adult: $\mathrm{A}=$ anterior part of body, lateral view (pteromorph, gnathosoma and legs not shown); $\mathrm{B}=$ posterior part of body, lateral view; $\mathrm{C}=$ posterior view. Scale bar: $50 \mu \mathrm{m}$ 
Table 1. Leg setation and solenidia of adult Allogalumna paramadagascarensis sp. n. and A. paravojnitsi sp. n.

\begin{tabular}{|c|c|c|c|c|c|}
\hline Leg & $\operatorname{Tr}$ & $\mathrm{Fe}$ & $\mathrm{Ge}$ & $\mathrm{Ti}$ & $\mathrm{Ta}$ \\
\hline I & $v^{\prime}$ & $d_{1}(l), b v^{\prime \prime}$ & $(l), v^{\prime}, \sigma$ & $(l),(v), \phi_{1}, \phi_{2}$ & $\begin{array}{c}(f t),(t c),(i t),(p),(u),(a), s,(p v), v^{\prime},(p l), l^{\prime \prime}, \\
\varepsilon, \omega_{1}, \omega_{2}\end{array}$ \\
\hline II & $v^{\prime}$ & $d,(l), b v^{\prime \prime}$ & $(l), v^{\prime}, \sigma$ & $(l),(v), \phi$ & $(f t),(t c),(i t),(p),(u),(a), s,(p v), \omega_{1}, \omega_{2}$ \\
\hline III & $v^{\prime}$ & $d, e v^{\prime}$ & $l^{\prime}, \sigma$ & $l^{\prime},(v), \phi$ & $(f t),(t c),(i t),(p),(u),(a), s,(p v)$ \\
\hline IV & $v^{\prime}$ & $d, e v^{\prime}$ & $d, l^{\prime}$ & $l^{\prime},(v), \phi$ & $f t^{\prime \prime},(t c),(p),(u),(a), s,(p v)$ \\
\hline
\end{tabular}

Note: Roman letters refer to normal setae, Greek letters to solenidia (except $\varepsilon$ =famulus). Single prime (') marks setae on anterior and double prime (") setae on posterior side of the given leg segment. Parentheses refer to a pair of setae.

pairs of adoral setae (10-12) setiform, roughened. Length of palp: 69-73. Axillary saccule distinct, elongated. Postpalpal seta (4) spiniform, smooth. Length of chelicera: 98-106. Two cheliceral setae setiform, barbed, cha (28-32) longer than chb (18-20). Trägårdh's organ of chelicera long, elongate triangular.

Epimeral and lateral podosomal regions (Figs 1B, 2A). Anterior margin of epimere I smooth. Pedotectum I broadly rounded, pedotectum II quadrangular, rounded distally in ventral view. Discidium triangular. Circumpedal carina slightly visible, thin, directed to seta $3 b$, but distinctly not reaching it. Epimeral setal formula: 1-0-1-2. Epimeral setae setiform, thin, smooth, $1 b$ and $3 b(10)$ longer than $4 a$ and $4 b(8)$.

Anogenital region (Figs 1B, 2A-C). Six pairs of genital $\left(g_{1}, 14 ; g_{2^{\prime}}, 10 ; g_{3}-g_{6^{\prime}}, 6\right)$, one pair of aggenital (6), two pairs of anal (6) and three pairs of adanal (6) setae setiform, thin, smooth. Anterior edge of genital plate with two setae. Aggenital seta inserted between genital and anal apertures, closer to the former. Adanal lyrifissure located close and parallel to anal plate. Adanal setae $a d_{1}$ and $a d_{2}$ postanal, $a d_{3}$ paraanal and lateral to iad. Distance $a d_{1}-a d_{2}$ shorter than $a d_{2}-a d_{3}$. Unpaired postanal porose area oval $(18-20 \times 6-8)$.

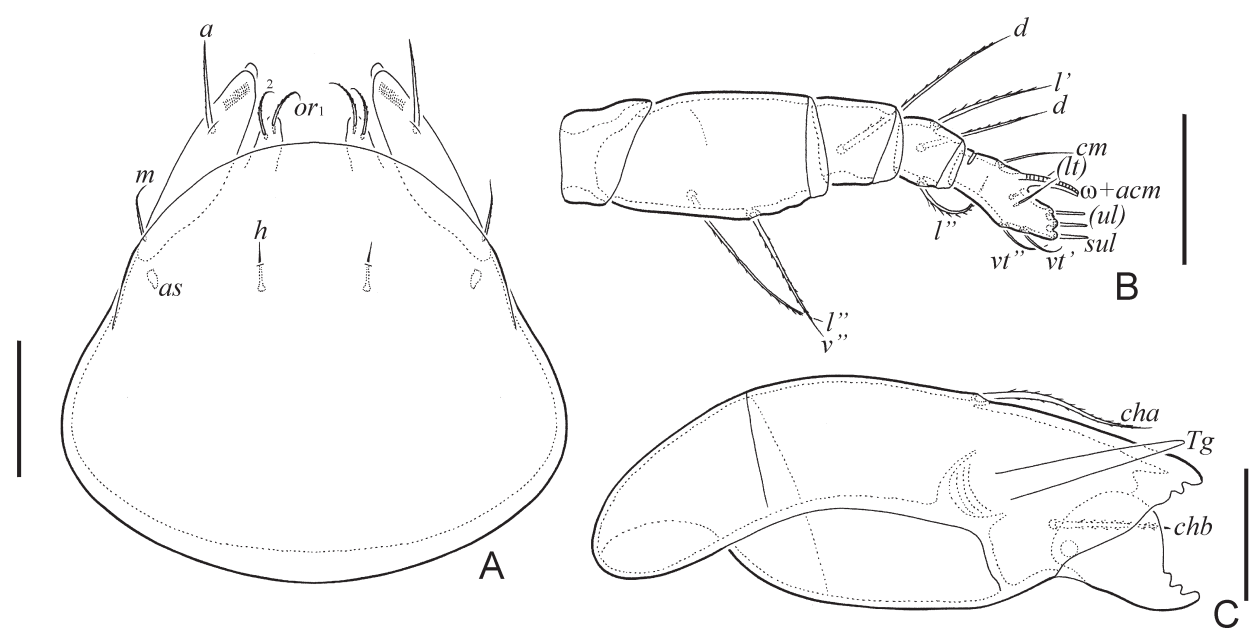

Fig. 3. Allogalumna paramadagascarensis sp. $\mathrm{n}$. , adult: $\mathrm{A}=$ subcapitulum, ventral view; $\mathrm{B}=$ palp, left, paraxial view; C = chelicera, left, paraxial. Scale bars: $20 \mu \mathrm{m}$ 
Legs (Figs 4A-D). Median claw distinctly thicker than laterals, all smooth on dorsal side. Porose area on all femora and on trochanters III, IV well visible. Formulas of leg setation and solenidia: I (1-4-3-4-20) [1-2-2], II (1-4-3-4-15) [1-1-2], III (1-2-1-3-15) [1-1-0], IV (1-2-2-3-12) [0-1-0]; homology of setae and solenidia indicated in Table 1. Famulus on tarsus I inserted lateral to solenidion $\omega_{1}$. Solenidion of tibia IV inserted in the middle of the segment.

Material examined. Holotype (female) and four paratypes (two females and two males): Madagascar, Montagne d'Ambre National Park, circuit Ampijoroana, evergreen
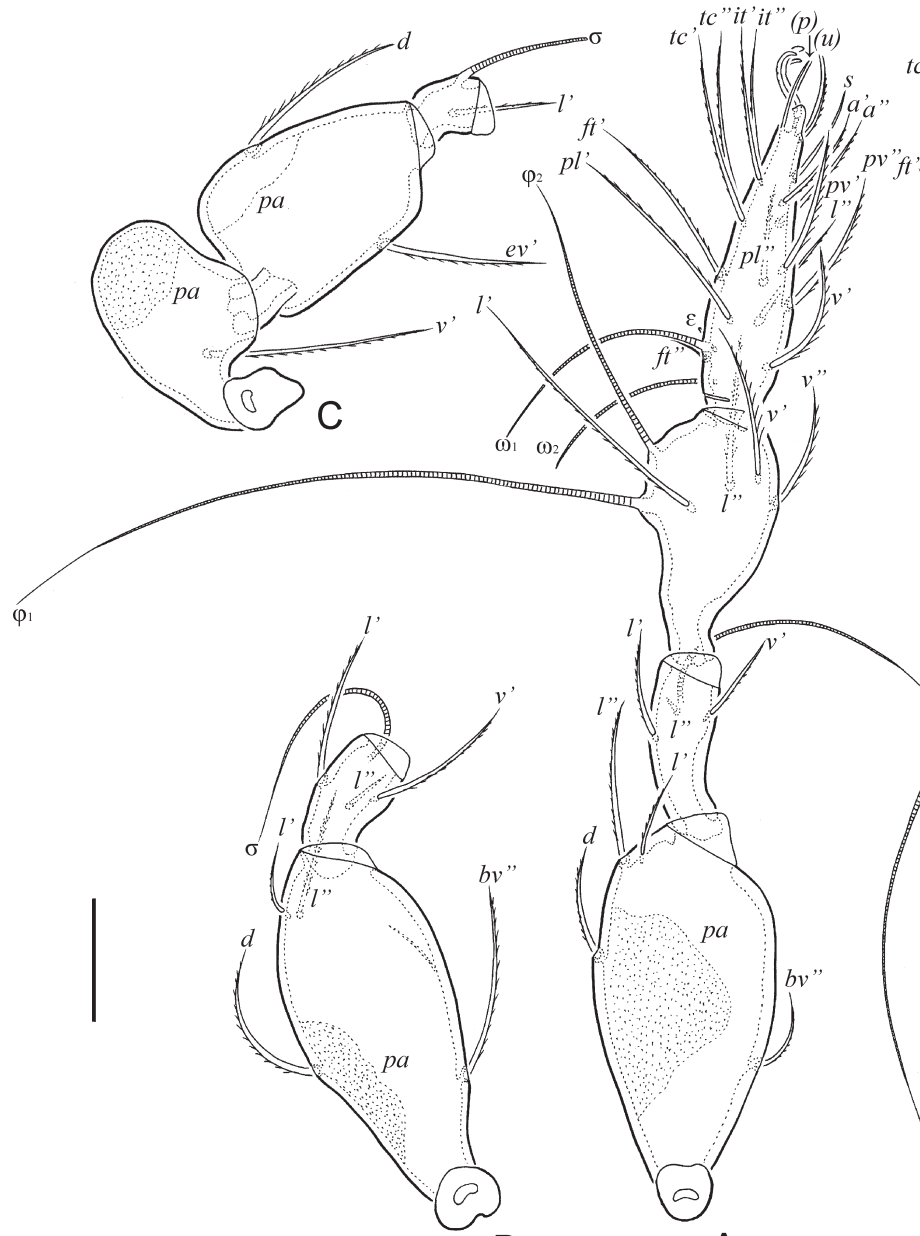

B

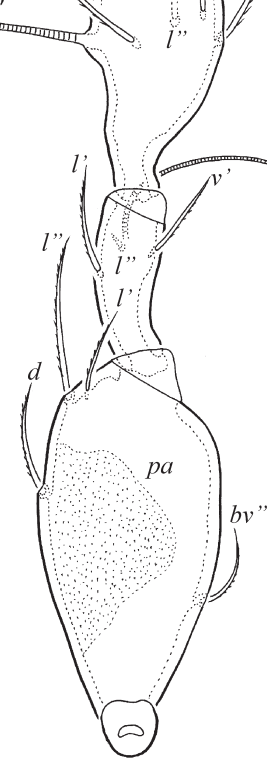

A

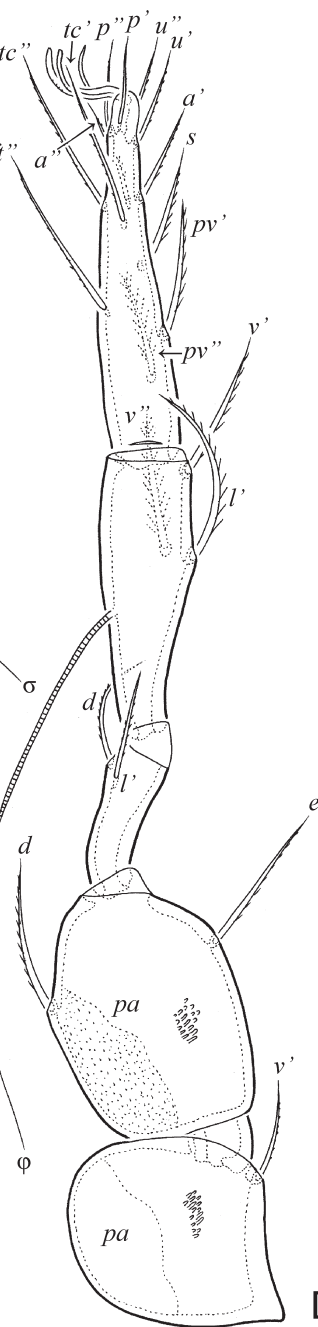

Fig. 4. Allogalumna paramadagascarensis sp. n., adult: $\mathrm{A}=$ leg $\mathrm{I}$, without trochanter, left, paraxial view; $\mathrm{B}=$ femur and genu of leg II, left, paraxial view; $\mathrm{C}=$ trochanter, femur and genu of leg III, right, paraxial view; D = leg IV, left, antiaxial view. Scale bar: $20 \mu \mathrm{m}$ 
rain forest, $12^{\circ} 31^{\prime} 28^{\prime \prime} \mathrm{S}, 4^{\circ} 09^{\prime} 52^{\prime \prime} \mathrm{E}, 950 \mathrm{~m}$ a.s.l., sifting of leaf litter sample under big unidentified tree, Winkler apparatus extraction, 13.I.2014 (R. Ravebolun and L. Rabotenoson).

Type deposition. The holotype is deposited in the collection of the Senckenberg Institute, Görlitz, Germany. Four paratypes are deposited in the collection of the Tyumen State University Museum of Zoology, Tyumen, Russia. All specimens are preserved in ethanol with a drop of glycerol.

Etymology. The species name paramadagascarensis refers to the similarity between the new species and Allogalumna madagascarensis (Balogh, 1960).

Remarks. Allogalumna paramadagascarensis sp. n. is morphologically similar to Allogalumna madagascarensis (Balogh, 1960) from Madagascar (see BALOGH 1960, MAHunkA 1996) in having small body size, bothridial seta dilated and ciliate unilaterally, rostral seta of medium size, lamellar and interlamellar setae short, four pairs of notogastral porose areas, median pore, and the absence of dorsosejugal suture. However, the new species differs from A. madagascarensis by the presence of rounded notogastral porose areas $A a$ (versus distinctly elongate triangular, transversely oriented).

Also, A. paramadagascarensis sp. n. is morphologically similar to Allogalumna longula (Balogh, 1960) from Madagascar (see BALOGH 1960) in having a small body size, bothridial seta dilated and ciliate unilaterally, lamellar and interlamellar setae short, four pairs of rounded notogastral porose areas, and the absence of dorsosejugal porose area. However, the new species differs from A. longula by the presence of an oval postanal porose area (versus bandlike, unusually long), median pore (versus absent) and rostral setae of medium size (versus short), and the localization of notogastral porose areas $A 1$ (dorsomedially versus laterally on the notogaster).

\section{Allogalumna paravojnitsi sp. n.}

$$
\text { (Figs 5-6) }
$$

Diagnosis. Body size: 332-348 × 232-265. Rostrum rounded. Bothridial seta long, with long stalk and small, elongate head, truncated and ciliated apically. Rostral, lamellar and interlamellar setae setiform, smooth, ro of medium size, le and in short. Dorsosejugal porose area oval. Dorsosejugal suture absent. Four pairs of notogastral porose areas, $A a$ triangular, transversely oriented, others rounded. Median pore present. Epimeral and anogenital setae short, setiform, smooth. Postanal porose area oval. Solenidion of tibia IV inserted in the middle of the segment. Sexual dimorphism not observed.

Description. Measurements. Body length 348 (holotype, female), 332-348 (five paratypes, one female and four males); notogaster width 249 (holotype), 232-265 (five paratypes). No clear differences between females and males in body size.

Integument. Body color light brown. Body surface (including pteromorphs, subcapitular mentum, genital and anal plates, legs) sparsely microfoveolate (visible under high 
magnification, $\times 1000)$. All leg femora and trochanters III, IV with rounded or elongate tubercles antiaxially.

Prodorsum (Figs 5A, 6A). Rostrum broadly rounded. Sublamellar line slightly visible, thin, curving backwards. Prodorsal leg niches and lateral ridges of prodorsum well-developed. Rostral (26-28), lamellar (6-8) and interlamellar (2) setae setiform, thin, smooth, ro thickest. Bothridial seta (73-82) with long stalk and small, elongate head, truncated and ciliated apically. Exobothridial seta represented by alveolus. Dorsosejugal porose area (12$14 \times 6-8$ ) elongate oval, transversely oriented, located posterolateral to in.

Notogaster (Figs 5A, 6A-C). Dorsosejugal suture absent. Dorsophragma elongated longitudinally, with variable number of components. With 10 pairs of setal alveoli and four pairs of porose areas, $A a$ (length 24-32) triangular, transversely oriented, other porose areas rounded (6-10). Median pore present in both sexes, located between A1. All lyrifissures distinct, $i m$ located between $l m$ and $A 1$ and closer to the later, ip between $p_{1}$ and $p_{2^{\prime}}$ ih and ips close to each other, anterior to $p_{3}$. Opisthonotal gland opening located posterolateral to $A 1$ and distanced from it.
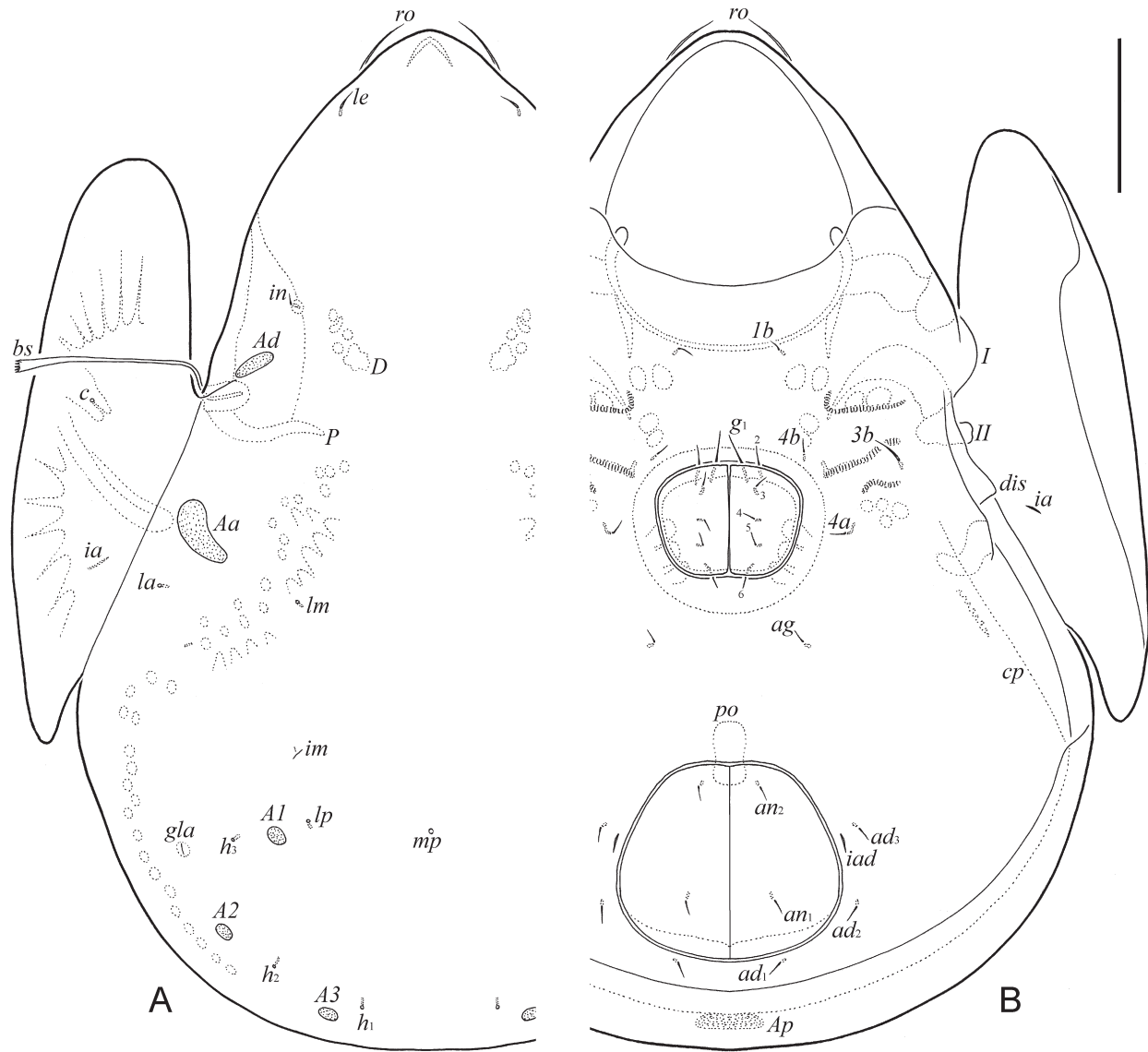

Fig. 5. Allogalumna paravojnitsi sp. $\mathrm{n}$., adult: $\mathrm{A}=$ dorsal view; $\mathrm{B}=$ ventral view (gnathosoma and legs not shown). Scale bar: $50 \mu \mathrm{m}$ 

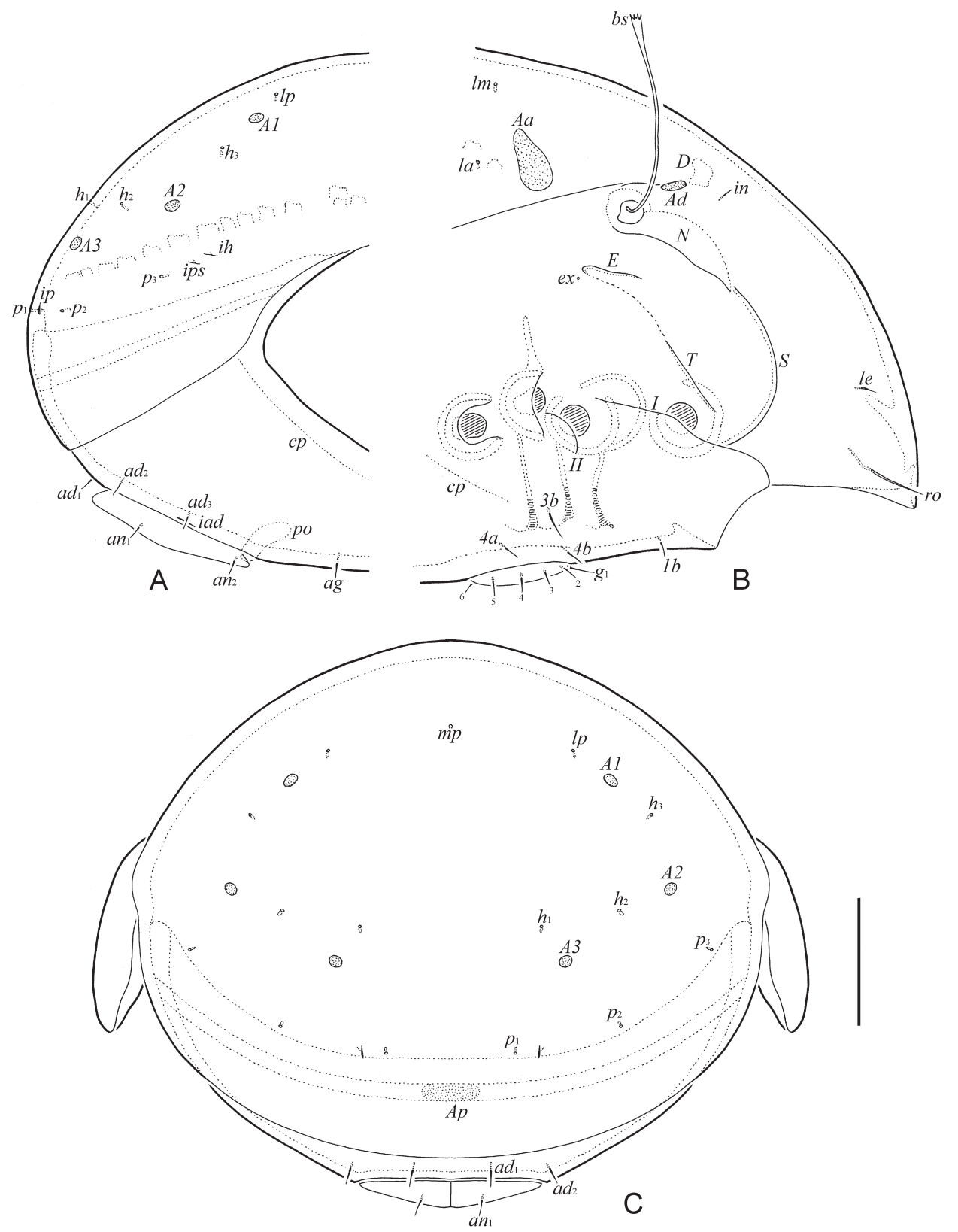

Fig. 6. Allogalumna paravojnitsi sp. n., adult: $\mathrm{A}=$ anterior part of body, lateral view (pteromorph, gnathosoma and legs not shown); $\mathrm{B}=$ posterior part of body, lateral view; $\mathrm{C}=$ posterior view. Scale bar: $50 \mu \mathrm{m}$ 
Gnathosoma. Generally, similar to Allogalumna paramadagascarensis sp. n. Subcapitulum longer than wide: 86-90 × 77-82. Three pairs of subcapitular setae setiform, smooth, $a(12-14)$ longer and thicker than $m(8-10)$ and $h(6)$. Two pairs of adoral setae (10-12) setiform, roughened. Length of palp: 69-73. Axillary saccule distinct, elongated. Postpalpal seta (4) spiniform, smooth. Length of chelicera: 102-106. Two cheliceral setae setiform, barbed, cha (30-32) longer than chb (18-20). Trägårdh's organ of chelicera long, elongate triangular.

Epimeral and lateral podosomal regions (Figs 5B, 6A). Anterior margin of epimere I smooth. Pedotectum I broadly rounded, pedotectum II quadrangular, rounded distally in ventral view. Discidium triangular. Circumpedal carina slightly visible, thin, directed to seta $3 b$, but distinctly not reaching it. Epimeral setal formula: 1-0-1-2. Epimeral setae setiform, thin, smooth, $3 b$ (10) longer than $1 b, 4 a$ and $4 b(6)$.

Anogenital region (Figs 5B, 6A-C). Six pairs of genital $\left(g_{1}, 10 ; g_{2}-g_{6}, 6\right)$, one pair of aggenital (6), two pairs of anal (6) and three pairs of adanal (6) setae setiform, thin, smooth. Anterior edge of genital plate with two setae. Aggenital seta inserted between genital and anal apertures, closer to the former. Adanal lyrifissure located close and parallel to anal plate. Adanal setae $a d_{1}$ and $a d_{2}$ postanal, $a d_{3}$ paraanal and lateral to $i a d$. Distance $a d_{1}-a d_{2}$ equal to $a d_{2}-a d_{3}$. Unpaired postanal porose area oval $(20 \times 6-8)$.

Legs. Generally, similar to Allogalumna paramadagascarensis sp. n. Median claw distinctly thicker than laterals, all smooth on dorsal side. Porose area on all femora and on trochanters III, IV well visible. Formulas of leg setation and solenidia: I (1-4-3-4-20) [1-22], II (1-4-3-4-15) [1-1-2], III (1-2-1-3-15) [1-1-0], IV (1-2-2-3-12) [0-1-0]; homology of setae and solenidia indicated in Table 1. Famulus on tarsus I inserted lateral to solenidion $\omega_{1}$. Solenidion of tibia IV inserted in the middle of the segment.

Material examined. Holotype (female) and five paratypes (one female and four males): Madagascar, Montagne d'Ambre National Park, circuit Ampijoroana, evergreen rain forest, $12^{\circ} 31^{\prime} 28^{\prime \prime} \mathrm{S}, 49^{\circ} 09^{\prime} 52^{\prime \prime} \mathrm{E}, 950 \mathrm{~m}$ a.s.l., sifting of leaf litter sample under big unidentified tree, Winkler apparatus extraction, 13.I.2014 (R. Ravebolun and L. Rabotenoson).

Type deposition. The holotype is deposited in the collection of the Senckenberg Institute, Görlitz, Germany. Five paratypes are deposited in the collection of the Tyumen State University Museum of Zoology, Tyumen, Russia. All specimens are preserved in ethanol with a drop of glycerol.

Etymology. The species name paravojnitsi refers to the similarity between the new species and Allogalumna vojnitsi Mahunka, 1993.

Remarks. Allogalumna paravojnitsi sp. n. is morphologically similar to Allogalumna vojnitsi Mahunka, 1993 from the Ethiopian region (see MAHUNKA 1993) in having small body size, bothridial seta with long stalk and short head truncated and ciliated apically, rostral seta of medium size, interlamellar setae short, four pairs of notogastral porose areas, median pore, and the absence of dorsosejugal suture. However, the new species differs from A. paravojnitsi by the presence of triangular notogastral porose areas $A a$ (versus rounded) and short lamellar setae (versus medium size). 


\section{KEY TO SPECIES OF ALLOGALUMNA FROM MADAGASCAR}

1. Bothridial seta with developed head distally

- Bothridial seta setiform or dilated in median part

2. Notogastral porose area $A a$ triangular; bothridial seta with small, elongate head, truncated apically; body size: 332-348 × 232-265

A. paravojnitsi sp. n.

- Notogastral porose area Aa rounded; bothridial seta with comparatively large head, rounded apically

3. Notogaster strongly narrowed posteriorly; median pore absent; body size: 372-390 × 174-280 A. superporosa Mahunka, 1996

- Notogaster normal, broadly narrowed posteriorly; median pore present; body size: $252-296 \times 197-214$

A. pocsi Mahunka, 1996

4. Notogastral porose area $A a$ triangular

- Notogastral porose area $A a$ rounded

5. Notogastral porose areas $A 1$ and $A 2$ located very close to each other; bothridial seta with two to three cilia; body size: $394-428 \times 312-340$

A. insolita Mahunka, 1996

- $\quad$ Notogastral porose areas $A 1$ and $A 2$ removed from each other; bothridial seta with six to 10 cilia; body size: 301-354 × 261-274

Allogalumna madagascarensis (Balogh, 1960)

6. Genital and anal plates densely striate; body size: $542-598 \times 403-445$

A. costata Mahunka, 1996

- Genital and anal plates not densely striate

7. Postanal porose area band-like, unusually long; median pore absent; notogastral porose area $A 1$ located laterally on the notogaster; body size: $341 \times 210$

A. longula (Balogh, 1960)

- $\quad$ Postanal porose area oval; median pore present; notogastral porose area A1 located dorsomedially on the notogaster; body size: 315-348 $\times 232-265$ A. paramadagascarensis sp. $\mathrm{n}$.

Acknowledgements - We thank to R. Ravebolun and L. Rabotenoson who collected the soil and sifted litter samples in Madagascar; the Moravian Museum in Brno, Czech 
Republic, which kindly provided material for our study; and two anonymous reviewers for the valuable comments. Also, we would like to thank Dr. Lala Harivelo Ravaomanarivo Raveloson (University of Antananarivo, Faculty of Sciences, Department of Entomology), Dr. Mamy A. Rakotoarijaona (Directeur des Opérations, Madagascar National Parks, Antananarivo) and Dr Dimby Raharinjanahary (Chargé des Bases de données de suivibiodiversité et recherche, Madagascar National Parks, Antananarivo) for supporting joint research project (2009-2014) entitled: “Étude à long terme de la biodiversité des groupes choisis d'insectes et d'acariens: Coléoptères, Hétéroptères, Homoptères, Acari, Lépidoptères et quelque famille de Micro Lépidoptères nocturne dans les localités préalablement sélectionnées en considération de la recherche et la protection de la biodiversité dans les aires protégées de Madagascar. Analyse des risques potentiels d'influencer négativement la biodiversité dans les régions étudiées". The presented research was supported by Czech Academy of Sciences (Research Plan No. RVO: 60077344).

\section{REFERENCES}

Balogh, J. (1960): Oribatides (Acari) nouveaux de Madagascar (1 $1^{\text {re }}$ série). - Mémoires de l'Institut Scientifique de Madagascar, Série A 14: 7-37.

Ermilov, S. G. \& Klimov, P. B. (2017): Generic revision of the large-winged mite superfamily Galumnoidea (Acari, Oribatida) of the world. - Zootaxa 4357: 1-72. http://dx.doi. org/10.11646/zootaxa.4357.1.1

Grandjean, F. (1936): Les Oribates de Jean Frédéric Hermann et de son père (Arachn. Acar.). - Annales de la Société Entomologique de France 105: 27-110.

JAсот, A. P. (1925): Phylogeny in the Oribatoidea. - American Naturalist 59: 272-279. https:// doi.org/10.1086/280038

JАсот, A. P. (1935): Galumna alatus Willmann (Acari, Oribatidae). - The Annals and Magazine of Natural History (10) 15: 489-492. https://doi.org/10.1080/00222933508654990

MahunKa, S. (1993): A new series of publication on new or little known oribatid taxa from Africa (Acari), I. - Acta Zoologica Hungarica 39: 91-119.

Mahunka, S. (1996): Galumnatoid taxa (Acari: Oribatida) from Madagascar (Part I). - Acta Zoologica Academiae Scientiarum Hungaricae 42: 163-181.

Received November 4, 2019, accepted February 13, 2020, published May 15, 2020 